\title{
Interview
}

\section{Interview with ELIP Managing Editor, Madison Edgar}

An audio version of this interview is available in the online version of this issue.

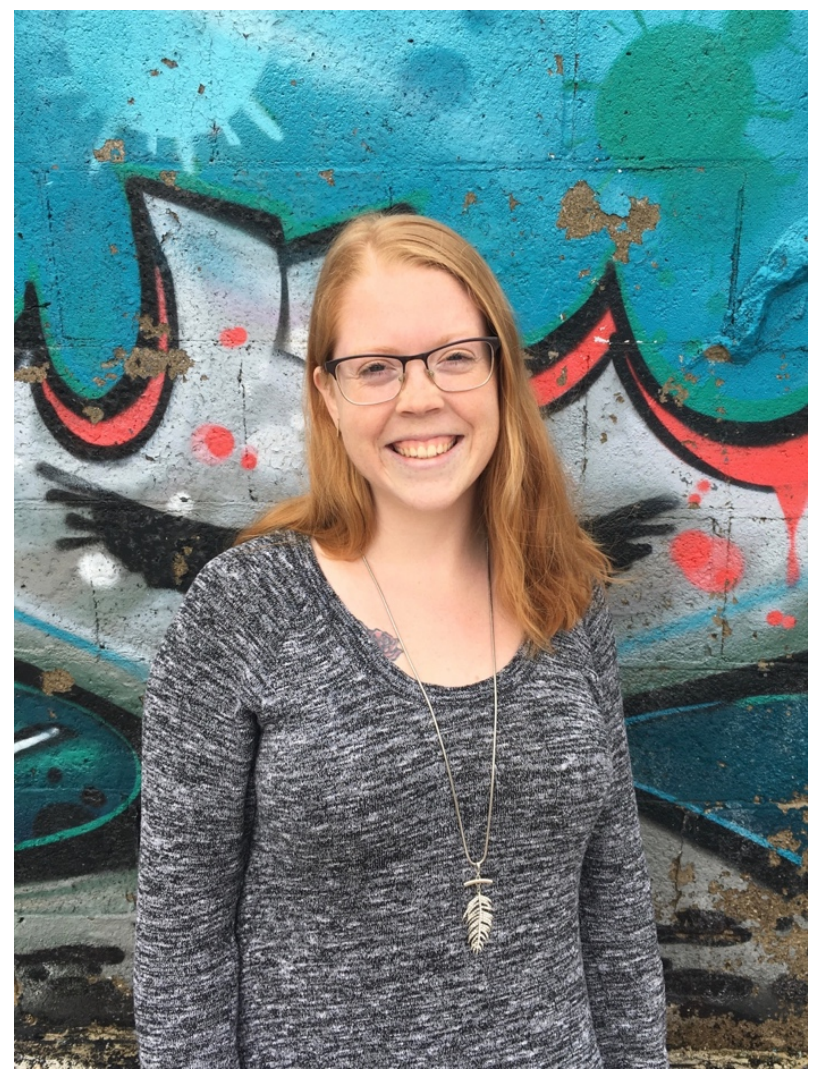

\section{Introduction}

This interview is to introduce the first issue of the new open access, peer-reviewed journal Emerging Library \& Information Perspectives! ELIP is run by students in the Master of Library and Information Science program and is published by the FIMS Graduate Library and hosted by Western Libraries. I'm here with Madison Edgar, current Managing Editor, to talk a little bit about this exciting new endeavour! 


\section{What is your background?}

I'm a Master of Library and Information Science candidate at the Faculty of Information and Media Studies at Western, and I also work as a Student Library Assistant at the FIMS Graduate Library.

How and when did you become the Managing Editor of ELIP?

At the FIMS Graduate Library, the student assistants are responsible for special projects in addition to being involved with day-to-day library activities. Marni Harrington, librarian and Advisor to ELIP's Editorial Team, approached me in the fall of last year (2017) to see if I would be interested in taking on the position of Managing Editor (for the inaugural issue). At that point, she had observed the way I worked and felt that I was a good fit for the role.

ELIP publishes a variety of content in addition to articles - such as book reviews, interviews, For the Field, and In the Field. What does this mean for the journal? I think that including a variety of types of content allows the journal to reach a broader audience and have a greater impact on the field of library and information science. Scholarly articles receive a lot of recognition for their role in advancing the field, as they should, but ELIP also recognizes the benefits of these other types of publications for scholars and professionals. Book reviews inform collection development as well as reading for professional development, and interviews provide the chance to learn from actual conversations with people in the field. Our In the Field section provides a chance for authors to reflect on practical experience such as co-ops, and communicate to readers who may be interested in engaging in these experiences. The For the Field section is truly unique - as MLIS students are learning and engaging in coursework, 
research, professional development and other experience, this section encourages them to share new ideas that can be implemented in the field. It initiates new conversations and further connects students to practicing professionals and scholars.

These other types of content also help the journal reach more authors. Some MLIS students aren't interested in writing articles, and instead prefer to express their ideas and research in a different way. ELIP can still be a venue through which they can publish and contribute to scholarly conversation.

ELIP also accepts multimodal submissions such as audio, video and images. Why? (and/or why is this necessary?)

I think that multimodal publishing removes any constraints on authors' creativity, and it is also important in terms of accessibility. For example, submissions that are designed and created through audio are much more engaging for anyone with limited vision, and video submissions allow for the possibility of sign language to be included. This editorial interview is an example of a multi-modal submission. We have included an audio file, along with an image.

How can you ensure the long-term sustainability of the journal? ELIP is sponsored by the FIMS Graduate Library, so the journal can remain open access and not charge authors to publish their work. ELIP is hosted by Western Libraries with the support of Scholars Portal, and this is a technological framework that we feel is sustainable for the long run.

\section{What do you see for the future of ELIP?}

ELIP will always be a student-run endeavour. It's an opportunity for students to gain hands-on experience with different aspects of scholarly publishing, whether that 
experience is as an author, a peer-reviewer or an editor. This is our first issue, and I think that now we've laid a sustainable foundation for the journal to continue to grow and have its place in the field of library and information science. My hope is that students will continue to recognize the benefits of publishing their work so that their voices and ideas can be heard by readers and other researchers (whether they are library and information professionals or not).

\section{Closing}

Thank you, Madison, for joining us. Madison Edgar is the current Managing Editor of $E L I P$, and the first edition will be published soon.

\section{Zoe Landon and Madison Edgar}

